\title{
Alluvial Ultrahigh Pressure (UHP) macrodiamond at Copeton / Bingara (Eastern Australia), and Cempaka (Kalimantan, Indonesia)
}

\author{
L. Barron ${ }^{1}$, T.P. Mernagh ${ }^{2}$, R. Pogson ${ }^{1}$, and B.J. Barron ${ }^{4}$ \\ ${ }^{1}$ The Australian Museum, 6 College Street, Sydney, NSW 2010, Australia \\ ${ }^{2}$ Geoscience Australia, GPO Box 378, Canberra ACT 2601, Australia \\ ${ }^{4}$ Consulting Petrologist, 7 Fairview Avenue, St Ives, NSW 2075, Australia
}

Several million macrodiamonds were mined from paleoalluvial and alluvial deposits at Copeton Bingara (CB, MacNevin 1976), and at Cempaka (Spencer et al. 1988). The regional geology in these areas was assembled by accretion during Phanerozoic-Mesozoic, and Cretaceous periods of subduction respectively, see below. Diamonds from both areas are rounded, resorbed by more than $25 \%$. All previous work on

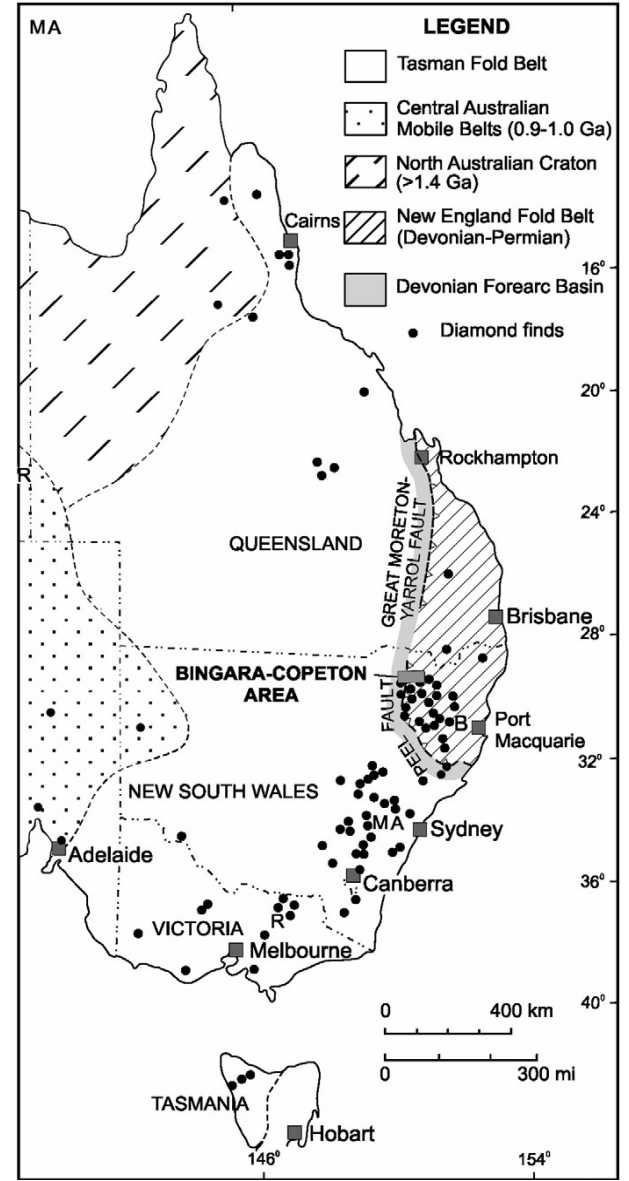

CB diamond has stressed its non-cratonic features (unique: growth structures; included minerals; high remnant internal pressures $\left(\mathrm{P}_{\mathrm{r}}\right)$ on inclusions such as 7.5 - $25 \mathrm{kbar}$ on pyroxene and garnet). See next graph for nitrogen characteristics of diamond from Copeton (Meyer et al. 1997) and Bingara (Davies 1996). B1 and $\mathrm{C} 1$ are complexly zoned white stones, whereas B2 and $\mathrm{C} 2$ are unzoned and tend to be yellow. The dashed lines are isomaturity trends for nitrogen aggregation, arising from a combination of deformation (during growth and storage) and storage (time, temperature). The data used to define the $\mathrm{CB}$ balloons can be recalculated as time-equivalent nitrogen maturity

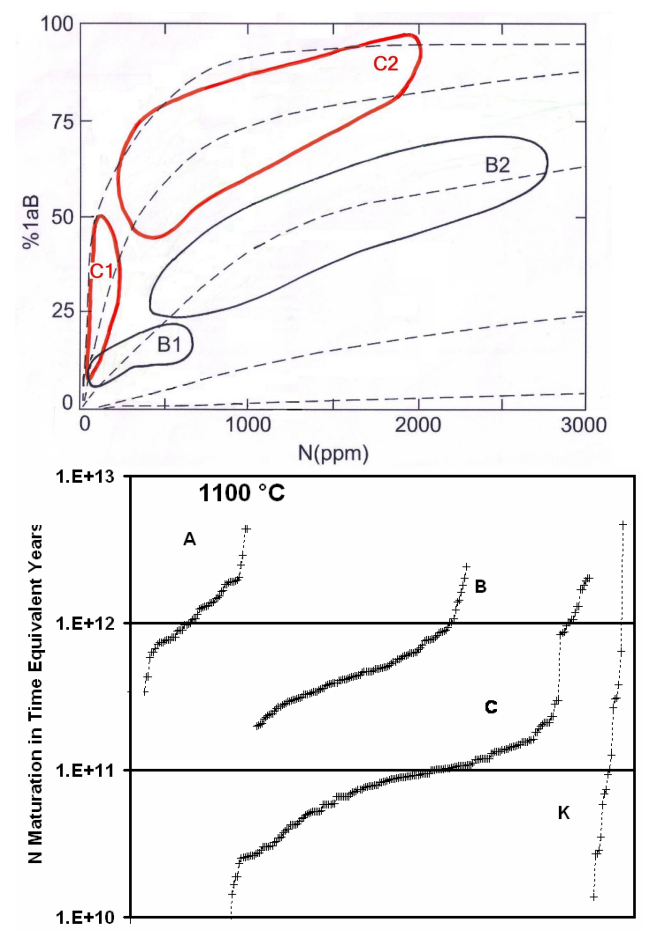

points, see above. Within each suite, the data is sorted by increasing maturity. Each trend has a spread on the $\mathrm{X}$ axis equal to the number of data points, whereas the spread on the $\mathrm{Y}$ axis represents the range in maturity values. The A trend (63 data points from 59 diamonds in one peridotite xenolith, Thomassot et al., 2007) is for a single simple history of diamond formation/storage, and acts as a natural "null hypothesis", with the low-slope central portion representing most of the data. Using the vertical range of this central portion of A as a yardstick, there is about the same range in the trends for B (198 points), C (116), and $\mathrm{K}$ (Cempaka in Kalimantan, 17), data after Meyer et al. (1997) and Davies (1998, B and K data). Each suite plots within "error" of a single but different maturation curve. Davies states that deformation is common in Bingara diamond and has strongly accelerated the aggregation of nitrogen, preventing 
maturation values from being used as an indicator of storage conditions. Copeton and Cempaka stones are also strongly deformed. The nitrogen characteristics indicate a correlation between Copeton and Bingara diamond that overlaps with Cempaka diamond .

See below for Raman spectra (first order and second order-inset) of diamond, with an arbitrary intensity scale. The full baseline spectrum is a digitised version of the Raman spectrum of low luminescent type IA cratonic diamond (after Gillet et al. 1998). The inset for diamond powder (b, synthetic) is from Semchinova et al. (1997) but compares well with spectra for cratonic and theoretical diamond (after Strauch et al., 1996). For cratonic diamond, the ratio of noise to peak height is about 30 . Note that a fine grainsize in the diamond divides this ratio by about 10 , by increasing the noise.
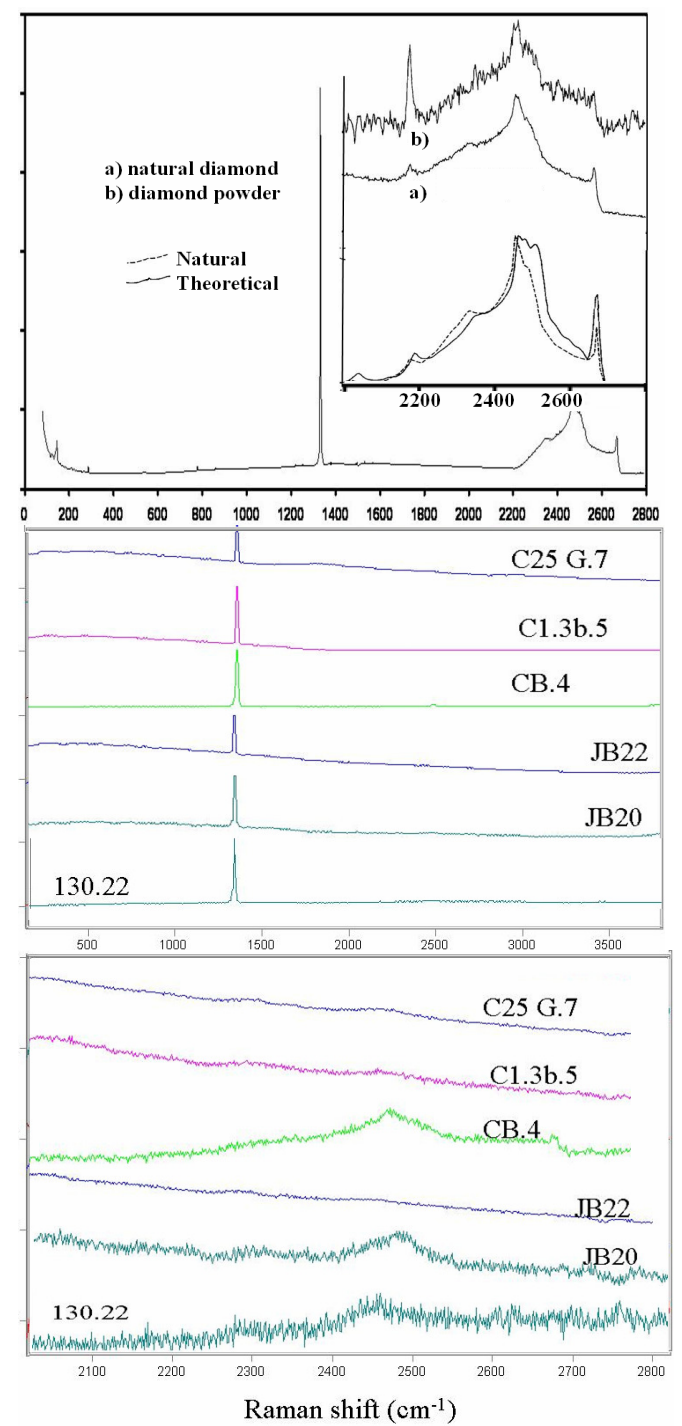

The two coloured graphs above show Raman spectra of our low-fluorescent diamond (top 3 spectra are from Cempaka, bottom 3 are from Copeton and Bingara). These second order Raman peaks have peak to noise ratios of 2 to 4 , dramatically reduced compared with those from cratonic and perfect diamond. These and 30 more Raman results are consistent with a non-cratonic origin for the $\mathrm{CB}$ and Cempaka diamonds. XRD of Copeton diamond indicates a unit cell $\mathrm{a}=3.567$ and density $=3.515 \mathrm{gm} / \mathrm{cc}$, both values normal. The reported absence of second order Raman peaks for nano- and micro-diamond from non-cratonic sources (UHP, Hawaii, Japan) may arise from an analogous small peak swamped by noise due to small grainsize.

The PT formation conditions for Copeton diamond can be defined from the intersection of two or more inclusion entrapment loci. These are determined from $\mathrm{P}_{\mathrm{r}}$ values on sealed inclusions in Copeton diamond, see below. Relative to the diamond/graphite (D/G) transition, the loci are for coesite (solid), diopside (dashed), garnet (dotted) and carbonate (dot dashed),

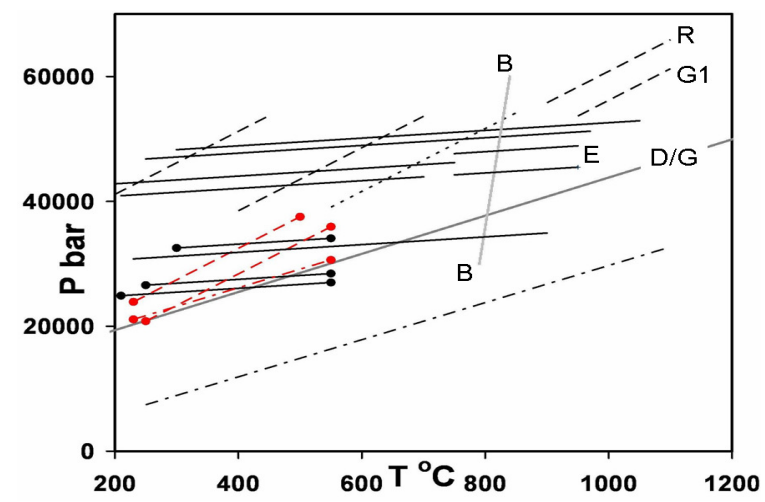

one inclusion per diamond. The B-B locus (Davies 1998) is based on the chemistry of grossular and diopside inclusions in Bingara diamonds. Short lines with solid dots are for multiple inclusions in one Copeton diamond (MR2/8), and are red if $\mathrm{P}_{\mathrm{r}}$ is estimated from strain birefringence (Barron et al., 2008). Also shown are short loci for diamond from elsewhere in NSW (Emmaville-E; Mount Airly-G1) and Victoria (R). For $\mathrm{CB}$ diamond, the highest pressure intersections restrict diamond formation conditions to $48( \pm 4) \mathrm{kb}$ and temperatures between 250 to 800 $( \pm 100){ }^{\circ} \mathrm{C}$ (Barron et al., in press). These formation conditions and unique features of the included minerals confirm these are ultrahigh pressure (UHP) macrodiamond. Diamond was formed at peak metamorphism during termination of subduction (colder ocean slab was host for CB2 diamond) by collision with an incoming hotter continent (subducted host for CB1 diamond). Non-peak diamond growth is also indicated - growth structures combined with lower $\mathrm{P}_{\mathrm{r}}$ values in the core of diamond (e.g. MR2/8) indicate that some prograde growth occurred just above the graphite diamond boundary at $400{ }^{\circ} \mathrm{C}$. Preliminary studies on Cempaka diamond have confirmed similar unique values for pyroxene inclusions of $\mathrm{P}_{\mathrm{r}}>7.5 \mathrm{~kb}$, indicating 1) a similar low temperature UHP origin and that 2) Ar age dates on pyroxene inclusions should be interpreted as ages of formation. 
Across the Bingara district, Mesozoic basanitic complexes carry abundant mantle-formed garnet grains captured from eclogite-dominated UHP domains stranded in the mantle and deep crust (Barron et al., 2005). Shiny surfaces, etched percussion marks, and numerous ruptured inclusion chambers in $\mathrm{CB}$ diamond indicate high temperature magmatic delivery, captured from these stranded UHP domains.

In Kalimantan (southern Borneo), rounded white and yellow diamonds are found in gravels and conglomerates downstream from terranes accreted to the edge of the Sundaland basement during Cretaceous subduction, including ophiolitic mountain ranges (see Spencer et al., 1998; Parkinson et al., 1998). Cempaka (SE Kalimantan) is the largest known diamond-bearing paleoplacer deposit in Indonesia. For Cempaka, the

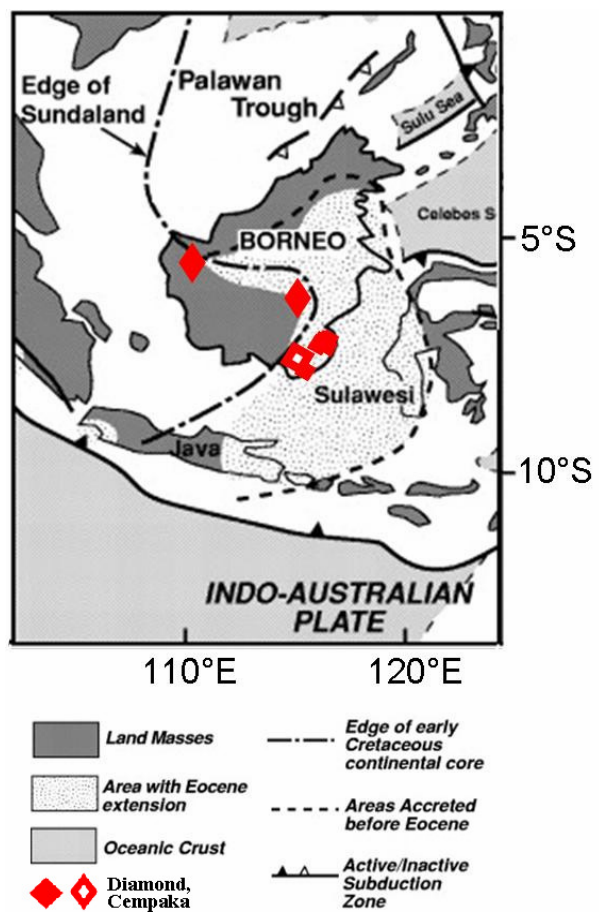

presence of 1) detrital mantle-formed zircon of lamproitic affinity (early and late Cretaceous ages, Graham et al., 2006), and 2) ballas with overcoattrapped inclusions of quartz, chamosite, Cr-magnetite, Y-xenotime, LREE-phosphate, salt, and KFeAlSi oxide ?glass suggest there may be chemical deposition during alluvial storage, and more than one type of volcanic source (including lamproite). Thus the diamond formation (post-250MA UHP metamorphism during subduction termination) and compound delivery mechanism (failed exhumation, non-kimberlitic postarc intrusion) appear to be analogous for the two regions. Brown/green radiation spots are abundant on more than a quarter of the 300 Cempaka diamonds studied, requiring multiple periods of alluvial confinement and heating, so the alluvial history of Cempaka diamond is complex. Such features are rare on $\mathrm{CB}$ diamond, so the alluvial history of $\mathrm{CB}$ diamond is simpler, and more proximal.

\section{Acknowledgements}

Diamonds were loaned by G. White (130.22), C. Ribeaux (G1), Victorian Museum (R), Cempaka (L. Spencer, P.T. Gualuh Cempaka), and Copeton Bingara (P. Kennewell, Cluff Resources N.L.), the latter stones donated to the Australian Museum collection. Financial assistance from the 9IKC is much appreciated.

\section{References}

Barron, B.J., Barron, L.M., Duncan, G., 2005. Eclogitic and Ultrahigh-Pressure Crustal Garnets and their relationship to Phanerozoic subduction Diamonds, Bingara area, New England fold belt, Eastern Australia. Economic Geology, 100, 1565-1582.

Barron, L.M., Barron, B.J., Mernagh, T.P., 2008. Using strain birefringence in diamond to estimate the remnant pressure on an inclusion. Australian Journal of Earth Sciences, 55, 159-165.

Barron, L.M., Barron, B.J., Mernagh, T.P., Birch, W.D., in press. Ultrahigh pressure macro diamonds from Copeton (New South Wales, Australia), based on Raman spectroscopy of inclusions. Ore Geology Reviews, pp11.

Davies, R.M., 1998. The characteristics and origins of alluvial diamonds from Eastern Australia. Unpublished Ph.D. thesis, Macquarie University, Sydney Australia.209 pp. +9 appendices.

Gillett. P., Hemley, R.J., McMillan, P.F.,1998 Vibrational properties at high pressures and temperatures in Reviews in Mineralogy, 37: Ultrahigh Pressure Mineralogy. Chapter 17, ed R.J. Hemley, 525-590.

Graham, I. Spencer, L., Barron, L.M., Gregory Yaxley, G., 2006. Nature and possible origin of the Cempaka Diamond deposit, Southeastern Kalimantan, Indonesia. IAGOD Meeting, Moscow, pp6.

MacNevin, A.A., 1977. Diamonds in New South Wales. Geological Survey of New South Wales. Mineral Resources, 42, $125 \mathrm{pp}$

Meyer, H.O.A., Milledge, H.J., Sutherland, F.L., Kennewell, P., 1997. Unusual diamonds and unique inclusions from New South Wales, Australia. Russian Geology and Geophysics, 38 (2), 305-331.

Parkinson, C. D., Miyazaki, K., Wakita, K., Barber, A. J., Carswell, D. A., 1998. An overview and tectonic synthesis of the pre-Tertiary very-high-pressure metamorphic and associated rocks of Java, Sulawesi and Kalimantan, Indonesia. The Island Arc, 7, 184-200.

Semchinova, O.K., Davydov, V.Y., Neff, H., Smirnov, E.P, Holzhuter, G., 1997. Formation of lowporosity compact diamond ceramics. Carbon, 35, 697-702.

Spencer, 1.K., Dikinis, S.D., Keller, P.C., Kane, R.E., 1988. The diamond deposits of Kalimantan, Borneo. Gems \& Gemology, summer, 67-80.

Strauch, D., Windl, W., Sterner, H., Pavone, P., Karch, K., 1996. Full ab initio calculation of second-order infrared and Raman spectra of elemental semiconductors. Physica B, 219\&220, 442-444.

Thomassot, E., Cartigny, P., Harris, J.W., Vijoen, K.S., 2007. Methane-related diamond crystallization in the Earth's mantle: Stable isotope evidences from a single diamond-bearing xenolith. Earth and Planetary Science Letters, 257, 362-371. 